\title{
Life-Cycle Assessment of Recycling Postconsumer High-Density Polyethylene and Polyethylene Terephthalate
}

\author{
Khaled M. Bataineh (iD \\ Department of Mechanical Engineering, Jordan University of Science and Technology, Irbid, Jordan \\ Correspondence should be addressed to Khaled M. Bataineh; k.bataineh@just.edu.jo
}

Received 28 September 2019; Revised 4 January 2020; Accepted 17 February 2020; Published 10 March 2020

Academic Editor: Hui Yao

Copyright ( $\odot 2020$ Khaled M. Bataineh. This is an open access article distributed under the Creative Commons Attribution License, which permits unrestricted use, distribution, and reproduction in any medium, provided the original work is properly cited.

\begin{abstract}
This study aims to quantify the overall environmental performances of mechanical recycling of the postconsumer high-density polyethylene (HDPE) and polyethylene terephthalate (PET) in Jordan. The life-cycle assessment (LCA) methodology is used to assess the potential environmental impacts of recycling postconsumer PET and HDPE. It quantifies the total energy requirements, energy sources, atmospheric pollutants, waterborne pollutants, and solid waste resulting from the production of recycled PET and HDPE resin from the postconsumer plastic. System expansion and cut-off recycling allocation methods are applied. The analysis has been carried out according to the LCA standard, series UNI EN ISO 14040-14044:2006. A standard unit of output (functional unit) is defined as "one ton of PET flake" and "one ton of HDPE pellet." The results of the production of virgin resin are compared with the "cut-off" and "system expansion" recycling results. Depending on the allocation methods applied, a nonrenewable energy saving of $40-85 \%$ and greenhouse gas emission saving of $25-75 \%$ can be achieved. Based on two allocation methods, PET and HDPE recycling offers important environmental benefits over single-use virgin PET and HDPE. LCA offers a powerful tool for assisting companies and policy-makers in the waste plastic industry. Furthermore, the "system expansion" recycling method is not easy to apply because it requires detailed data outside of the life cycle of the investigated product.
\end{abstract}

\section{Introduction}

Increasing plastic usage leads to both waste-management issues and environmental damages. In 2014, about 280 million tons of plastics were produced annually [1], while in 2015, it was 322 million tons [2]. Moreover, the world plastic production reached 335 in 2016 and almost reached 350 million tons in 2017 [2]. Using recycled plastics can significantly reduce the environmental impacts by limiting the exploration, mining, and transportation of natural gas and oil. Plastic recycling has a number of advantages, mainly (a) reducing fossil fuel consumption since plastic production uses $4-8 \%$ of global oil production where $4 \%$ is from using feedstock and another $4 \%$ during conversion $[2,3]$, (b) reducing energy and municipal solid waste (MSW), and (c) reducing the carbon dioxide $\left(\mathrm{CO}_{2}\right)$, nitrogen oxide $(\mathrm{NOx})$, and sulphur dioxide $\left(\mathrm{SO}_{2}\right)$ emissions.

Recently, the world is witnessing an increase in recycling rates for plastics despite several challenges. The world average amount of municipal solid waste (MSW) per inhabitant is about $440 \mathrm{~kg}$ yearly (for Jordan, the annual average is $380 \mathrm{~kg}$ ) [4]. The plastic forms about $7-8 \%$ by weight but a larger percentage by volume of the MSW stream [5]. The overall sustainability of the system depends on the residual level of material inputs, the energy inputs, and the effects of external impacts on ecosystems. Advances in technologies and systems for collecting, sorting, and reprocessing of recyclable plastics are creating new opportunities for recycling, and with the combined actions of the public, industries, and governments, it may be possible to divert the majority of plastic waste from landfills to recycling over the next few decades.

LCA can be a useful tool for assessing the potential benefits of recycling programs. It considers energy and material consumptions, emissions in the environment, and disposal of wastes, and it follows each activity from the extraction of raw materials to the return of wastes to the ground. LCA has been successfully applied to the mechanical 
recycling of waste plastics by focusing on comparison of different disposal alternatives [6-9]. It was found that the mechanical recycling of waste plastics is more preferable to incineration and landfills, provided a certain recycled material substitution ratio is achieved [6]. Furthermore, it was found that mechanical recycling is an environmentalfriendly approach for waste plastic disposal [6-9]. Recycling has been shown to save more energy than that produced by energy recovery even when including the energy used to collect, transport, and reprocess the plastic [10]. Life-cycle analyses for plastic-recycling systems concluded that greater positive environmental benefits can be achieved from mechanical recycling compared to landfill and incineration with energy recovery [11-14].

It has been reported that PET bottle recycling gives a net benefit in greenhouse gas emissions of 1.5 tons of $\mathrm{CO}_{2}$ equivalent per ton of recycled PET with energy-saving requirements [15]. A German life-cycle analysis (LCA) study found that most of the net energy and emission benefits are caused by the substitution of virgin polymer production [16]. A 27\% reduction in emissions can be achieved by using recycled PET instead of virgin PET for bottle manufacture [17]. The LCA results show that recycled PET fibers offer important environmental benefits over virgin PET fibers [18]. Furthermore, the study reported that depending on the allocation methods applied for open-loop recycling, fuel energy savings of $40-85 \%$ and global warming optional savings of $25-75 \%$ could be achieved. An LCA study is conducted by Arena et al. on the Italian system for mechanically recycling the postconsumer PE and PET liquid containers [12]. Their results indicated that the energy consumption for production of $1 \mathrm{~kg}$ of flakes of recycled PET is $7.97 \mathrm{MJ}$. Another life-cycle assessment study of PET bottles indicated that producing virgin $\mathrm{PET}$ resin requires an energy of $70830 \mathrm{MJ} /$ ton [18]. Burnley et al. [18] performed comparative LCA between closed-loop recycling and incineration (with energy recovery) of postconsumer PET wastes [19]. The results indicated that closed-loop recycled PET bottles reduce $\mathrm{CO}_{2}$, carbon monoxide, acid gases, particulate matter, heavy metals, and dioxins significantly. The reduction in emissions was mainly because of the reduction in emissions of manufacturing an equivalent mass of PET from virgin materials.

It has been reported that recycling plastic waste materials causes changes in their thermal and mechanical properties [20-27]. These changes may affect material processing conditions and the quality of the end products. Improving the quality of the recycled material has received significant attention from many researchers [20-27]. The quality of mechanically recycled PET and HDPE depends on the purity of the waste stream (which can be achieved by careful washing and sorting). Due to the fact that few researchers are dealing with recycled plastics, the recycled plastic is still ending up in low-value products. Furthermore, the lack of adequate investigations is responsible for the limited interest in the recycling of waste plastic scrap. Besides the awareness of the great potential usage of recycled plastics in many industries, little information can be found on assessing the environmental aspects of fabricating recycled plastics or composites for high-value applications or even everyday applications.

Although the approach of using LCA for assessing the overall environmental performances of postconsumer HDPE and PET has been previously investigated, the present work has global and regional interest. LCA results depend strongly on many local specific conditions, such as population behavior, government policies and regulations, population distribution, and population awareness [28]. Laurent et al. found out that most published studies have primarily been concentrated in Europe with little application in developing countries [28]. Laurent et al. stated that the "number of environmental problems specific to waste management in developing countries, e.g., occupational health impacts from informal collection and recycling, has not been investigated."

Mediterranean countries recognize the need for finding sustainable and innovative methods of selective waste collection and disposal [29]. These methods should consider several factors such as climate change, atmospheric and water pollution, and marine debris. To promote sustainable development in the partner countries, the Euro-Mediterranean Regional and Local Assembly (ARLEM) has continually emphasized the need for integrated environmental sustainability and appropriate infrastructure.

It is clear that this study is considered significant and important due to its geographic and local conditions. It is worth mentioning that the literature lacks deep investigations of the environmental impacts of the real practice of mechanical plastic recycling. The objective of this study is to quantify the overall environmental performances of mechanical recycling of postconsumer HDPE and PET in Jordan. It aims to answer key questions related to the current practice, the actual composition and related environmental impacts, and whether the environmental benefits of substituting virgin materials can offset the environmental burdens associated with plastic recycling. To address these knowledge gaps, this paper presents a detailed investigation of plastic recycling using the LCA methodology.

\section{Methodology}

Key elements of the LCA methodology include the study boundaries, resource inventory (raw materials and energy), emission inventory (atmospheric, waterborne, and solid waste), and disposal practices. The analysis has been carried out according to the LCA standard, series UNI EN ISO 14040-14044:2006 [30].

2.1. Goal and Functional Unit. An LCA quantifies the energy consumption and environmental emissions for a given product. Product requirements and their associated environmental emissions are determined and expressed in terms of a standard unit of output (functional unit). The functional unit is an important concept in LCA. It is used for comparative purposes. For two LCAs to be directly comparable, they must be based on the same functional unit which considers the actual function delivered by a product [31]. 
Laurent et al. encouraged the practitioners to include local specifications as well as any relevant aspects to guarantee the comparability of the systems [31]. In this study, a standard unit of output (functional unit) is defined as "one ton of PET flake" and "one ton of HDPE pellet." The chosen functional unit implies the assumption that the recycled PET flake and virgin PET flake are functionally equivalent. Moreover, it is assumed that the recycled HDPE pellet and virgin HDPE pellet are functionally equivalent. It is assumed that mechanically recycled PET and HDPE can reach the same quality as a virgin. Although it might argue that the recycled material might not reach the same quality as a virgin, as have been mentioned previously, there are several methods developed lately that enhance the quality of the recycled resin. It is worth mentioning that because PET and HDPE have a wide range of applications, it is always possible to find suitable applications for those recycled materials.

2.2. System Boundary. Many methods can be used to allocate environmental burdens among different useful lives of the material [32]. The "cut-off" and "system expansion" approaches are used for LCA in this study. In the "system expansion" allocation method, also known as "the end of life recycling" or "the avoided burden approach," the virgin material product and recycling product are allocated among a limited number of useful lives of the material $[33,34]$. In this method, the products for virgin material production, recovery and recycling, and ultimate disposal of the recycled material are shared among all the sequential useful lives of the material. The "cut-off" approach, also known as the "recycled content approach," creates a boundary between the first life (virgin product) and the second life (recycled product) and treats them as a separate system [34]. Figure 1 illustrates the concept of the "cut-off" approach: the first life and second life are cut into two independent product systems. Based on the "cut-off" principle, the used product from the first life is considered to be waste; waste does not bear any environmental burden from the first life. The "cut-off" rule has been widely used for recycled products [17, 33, 34]. The "cut-off" method is considered simple and easy to apply because no data of the first life are needed. In this analysis, the "cut-off" and "system expansion" approaches are used for LCA [32-34]. Two separate sets of results are developed using each of these approaches. It is worth mentioning that the advocates for the two approaches claim that they are compliant with current ISO standards 14040 and 14044 (2006 a,b) [30].

2.3. General Data and Assumptions. The geographic boundary in this study covers Jordan. All recycling companies are considered small-size enterprises. The quality of input data is extremely important in determining the accuracy of the study. Careful devotion to the data collection methodology determines not only data quality but also objectivity. Data necessary for conducting this analysis are separated into two categories: process-related data and fuelrelated data. Major data resources are material recovery facilities and a plastic-recycling facility. Further data sources are LCA databases, scientific publications, governmental publications, and personal communication.

The first step in the data-collecting process is the search of the literature to determine raw materials and processes necessary to produce the final product. Furthermore, the research expands to identify raw materials and processes used to produce these raw materials. As a result, a flow diagram is systematically constructed to represent the production pathway of each system. In order to guarantee the objectivity, each unit process in the life-cycle study is researched independently of all other processes. No calculations are performed to link processes together with the production of their raw materials until after data gathering and review are completed. Considering budget and limited industry participation, the data used in this work are believed to be the best that can be currently obtained. It is worth mentioning that each number contributes a small part to the total value, so a large error in one data point does not necessarily create a problem.

The average energy requirements are quantified in terms of fuel or electricity units, such as liters of diesel fuel, or kilowatt-hours $(\mathrm{kWh})$ of electricity. The fuel used to transport raw materials to each process is included in energy requirements. Transportation energy requirements are established in the conventional unit of ton- $\mathrm{km}$. The average efficiency of each transportation mode is used to convert from ton-km to fuel consumption by each transport mode (e.g., single truck $\left(16 \mathrm{~m}^{3}\right)$ and large truck $\left.\left(48 \mathrm{~m}^{3}\right)\right)$. Atmospheric emissions and solid wastes are considered environmental emissions in this study. Atmospheric emissions are due to the combustion of fuel for the process, transportation fuel, and emissions released from the process itself. These mainly include carbon dioxide, carbon monoxide, nonmethane hydrocarbons, nitrogen oxides, particulates, and sulphur oxides. The atmospheric emissions are expressed in $\mathrm{kg}$ of carbon dioxide equivalents. Solid wastes generated from all sources that are landfilled on the junk yard or disposed on the streets or other ways are considered in this study.

The fuel consumption for each transportation method is quantified. The equation used to convert the fuel units to an equivalent $\mathrm{kWh}$ is

energy consumption $=$ fuel consumption $\left(\frac{\mathrm{LHV} \cdot \text { deisel density }}{3600}\right)$,

where LHV is $43.1 \mathrm{MJ} / \mathrm{kg}$ and diesel density is $0.832 \mathrm{~kg} / \mathrm{m}^{3}$ [35]. Actual industry data and published emission standards are used as the basis for determining environmental emissions. The $\mathrm{CO}_{2}$ emission factor depends on the type of fuel [36]. $\mathrm{CO}_{2}$ emission is calculated depending on the type of vehicle and distance travel. The emission factor is estimated from the Environmental Protection Agency (EPA) emission factors [36].

2.4. Environmental Impact Assessment. In this study, global warming potential (GWP) and nonrenewable energy use (NREU) are considered environmental indicators. Global 


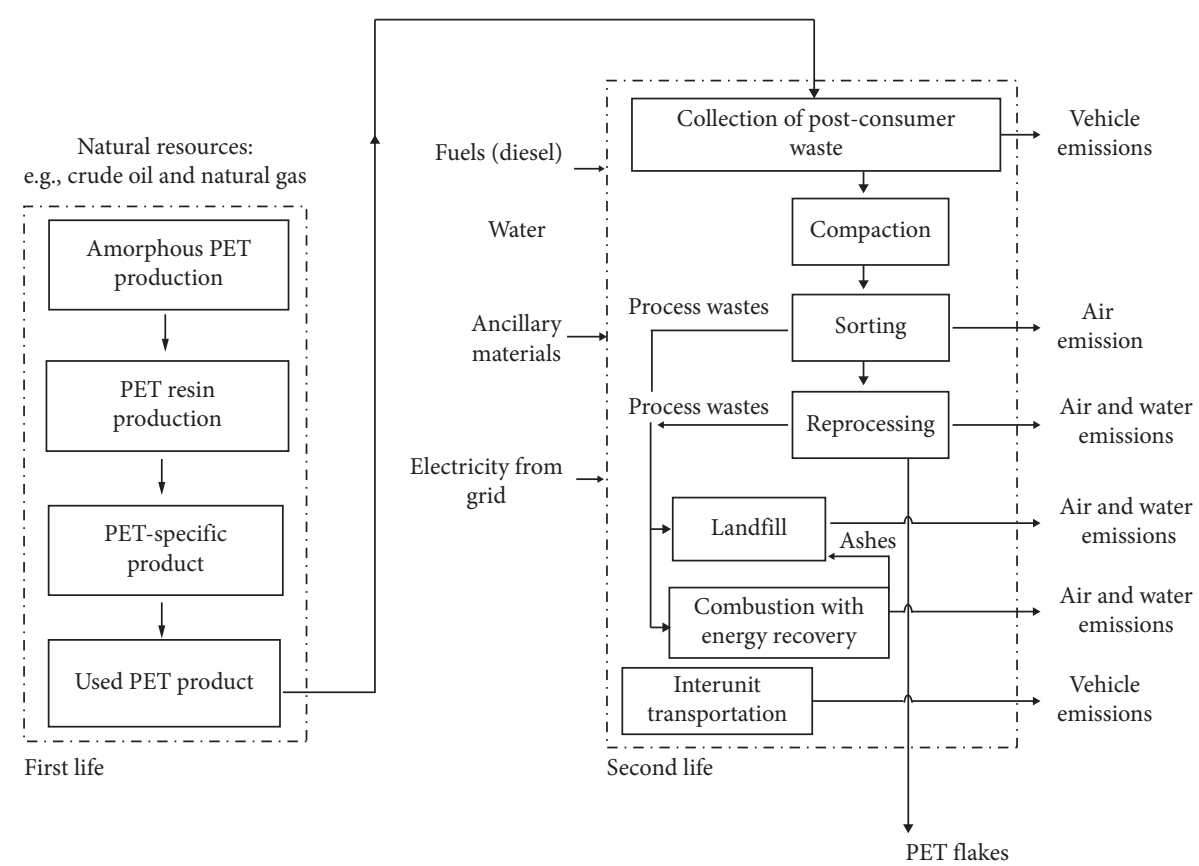

FIgURE 1: Life cycle recycling PET from waste PET, splitting the first life and the second life based on the "cut-off" approach.

warming potential impacts are calculated based on internationally accepted factors for various greenhouse gases. In life-cycle impact assessment, all emissions released by the product system to the environment and all raw material requirements are converted into environmental impact categories.

2.5. Recovery and Recycling Processes for Postconsumer PET and HDPE. Mechanical recycling of postconsumer PET and HDPE plastic is considered in this study. Thermoplastics including PET, PE, and PP all have high potential to be mechanically recycled. In this analysis, the production of postconsumer recycled PET and HDPE flakes is divided into five main stages:

(1) Collection of postconsumer plastics: this can be done by bringing plastics from the landfill or through curbside collections. A medium-size truck $\left(16 \mathrm{~m}^{3}\right)$ can make a route to collect wasted plastic from the curbside. A large-size truck can bring wasted plastic from both municipal solid waste (MSW) sites and junk yards.

(2) Sorting: automatic and manual methods can be used for sorting rigid recyclable plastics. Automated sorting is usually sufficient to separate the plastic from glass, metals, and paper.

(3) Size reduction and cleaning: rigid plastics are typically crushed and ground into chips and washed to remove food residues, pulp fibers, and adhesives. It has been reported that wash plants use only $3-5 \mathrm{~m}^{3}$ of water per ton of material. Moreover, new technology for cleaning such as dry cleaning which cleans surfaces through friction without using water can be utilized.
(4) Further separation: several separation techniques can be applied to the reduced size of plastic pieces. For example, sink/float separation in water can effectively separate polyolefin from PVC. The use of different media can allow for further separation. Air elutriation separation techniques can also be used for removing low-density films from denser ground plastics. Finally, laser-sorting systems can be used to remove other impurities such as silicones and nylon.

(5) Reclaimer operations: processing of the resin by a reclaimer converts the received material into clean resin ready to be converted into a product.

Residential curbside collection accounts for the majority of postconsumer plastic recovery. The fuel requirements for the curbside collection of wasted plastic were gathered from various sources. The weight of the collected material influences the fuel economy of the collection vehicle. The total quantity of recyclables per truck load was based on the number of households served per collection vehicle route, the average kilogram of recyclables set out per household per week, and the composition of generated recyclables.

Transport of wasted plastic from junk yards, MSW sites, and landfill to a material recovery facility (MRF) is modeled as a volume-limited load of loose items transported by $16 \mathrm{~m}^{3}$ and $48 \mathrm{~m}^{3}$ truck sizes. The fuel economy for a single truck $\left(16 \mathrm{~m}^{3}\right)$ is estimated as $34.5 \mathrm{~L} / 100 \mathrm{~km}$, while it is estimated as $37 \mathrm{~L} / 100 \mathrm{~km}$ for a larger truck. The average distance is estimated as $60 \mathrm{~km}$. The composition by volume for the weight of noncompacted household recyclables per collection route is shown in Table 1. The fuel consumption allocated for collecting recyclables on a volume basis is obtained by calculating the noncompacted volume for the weight of recyclables collected per vehicle route. A density factor based 
TABLE 1: Data for the curbside collection profile by weight for the recovery of PET and HDPE and data for composition by weight of materials collected per vehicle load.

\begin{tabular}{lc}
\hline Curbside collection profile by weight & \\
Truck fuel consumption $(\mathrm{L}) / 100 \mathrm{~km}$ & 34.5 \\
Route distance round trip $(\mathrm{km})$ & $60 \mathrm{~km}$ \\
Truck cubic meters $\left(\mathrm{m}^{3}\right)$ & 16 \\
Households per route & 950 \\
Average setouts per route & 310 \\
kg material per setout $(\mathrm{kg})$ & 6.5 \\
Material per load $(\mathrm{kg})$ & 2015 \\
\hline Truck load composition (by weight) & \\
PET & $10 \%$ \\
HDPE & $10 \%$ \\
PVC & $3 \%$ \\
Other plastics & $3.00 \%$ \\
Other papers & $27 \%$ \\
Corrugated containers & $8.50 \%$ \\
Glass & $11 \%$ \\
Steel & $15 \%$ \\
Al & $8 \%$ \\
Cu & $5 \%$ \\
Nonrecyclables & $9 \%$ \\
\hline
\end{tabular}

on the statistics study was used. The compacted densities and weight percentages of recyclables per collection route are shown in Table 2 . The volume-based fuel allocation shown in Table 3 is based on a compaction rate of 50 percent. Table 4 shows the total fuel use for the collection of each resin, based on the percentages that are collected by each method and the fuel used for each method.

The majority of sorting and separation of plastics take place at material recovery facilities (MRFs). The energy requirements were obtained based on data collected from MRFs and a PRF using data collection forms developed specifically for this study. Three completed MRF surveys and one completed PRF survey were received. Table 5 shows the estimated energy requirements for the incoming material transportation to the MRF and its operation. As with the MRF data sets, only the weighted average data sets can be shown in order to protect the confidentiality of individual facility data.

2.5.1. PET Reclamation. It is estimated that the incoming material travels an average of $60 \mathrm{~km}$ by truck. The majority of the incoming material received by PET reclaimers is from MRFs (83\%) and a plastic-recycling facility (PRF, 17\%). Most of the facilities received the postconsumer PET as individual bales. The bales must be broken down, and the material must be sorted to remove the foreign material. The sorted materials go through a prewashing stage before they are granulated to flakes. These flakes are washed to market specifications as part of the reclaimer processing operations. This is most often achieved with a caustic wash, but different reclaimers reported using a variety of washing chemicals including surfactants, defoamers, and wetting agents. Although the incoming material has undergone some presorting, other materials are mixed in with the PET. It is estimated that about 80 percent of the weight of the
TABLE 2: Truck load composition and uncompacted volume (for the $\mathrm{kg}$ of recyclables collected on a route).

\begin{tabular}{lc}
\hline Item collected & Uncompacted density $\left(\mathrm{kg} / \mathrm{m}^{3}\right)$ \\
\hline PET & 106 \\
HDPE & 106 \\
Other plastics & 106 \\
Paper & 340 \\
Corrugated containers & 340 \\
Glass & 600 \\
Steel & 1200 \\
Al & 420 \\
Cu & 450 \\
Nonrecyclables & 150 \\
\hline \multicolumn{3}{l}{} \\
TABLE 3: Fuel consumption for the curbside collection system. \\
\hline Method: weight basis & 2015 \\
kg of material per full load & 30 \\
Liter fuel per load & 14.9 \\
Liter fuel per $1000 \mathrm{~kg}$ of material collected & \\
\hline Method: volume basis & 9 \\
Cubic meters per load at $50 \%$ compaction of materials on & 9 \\
truck & \\
Liter fuel per m ${ }^{3}$ of material on truck & \\
Liter fuel per $1000 \mathrm{~kg}$ plastic at $50 \%$ compaction density & 28 \\
\hline
\end{tabular}

incoming material ends up as recycled PET resin. Unusable contaminants represent an average of 18.3 percent of the weight of the incoming material. The clean postconsumer PET is commonly sold in the flake form, or it can be pelletized. The material and energy requirements per 1 ton of the postconsumer PET flake output are listed in Table 6.

2.5.2. HDPE Reclamation. For the HDPE reclaimer facilities, the incoming material travels an average of $60 \mathrm{~km}$. The percentages of the incoming material received by HDPE reclaimers from MRFs are on average $92 \%$ with a smaller portion from PRFs. Most facilities received postconsumer HDPE as individual resin bales (on average 94\%). The bales must be broken down, and the material must be sorted to remove foreign materials. A typical processing sequence includes debaling, grinding, washing, drying, extruding, and pelletizing. All reclaimed flakes are washed as part of the reclaimer processing operations. Clean postconsumer HDPE is most commonly sold in the pellet form. The weighted average material and energy requirements for producing 1 ton of postconsumer recycled HDPE pellets are listed in Table 7.

\section{Life-Cycle Inventory Results}

The collected materials, energy requirements, and atmospheric emissions for the sequence of processes used to collect, transport, and process postconsumer PEP and HDPE products into clean recycled resin ready for use to manufacture a plastic product are presented in this section. The process data sets for each step are presented in the previous section. As mentioned previously, the "cut-off" and 
TABLE 4: Total fuel used for collection of 1 ton of the postconsumer plastic (including two methods).

\begin{tabular}{|c|c|c|c|c|}
\hline & \multirow{2}{*}{$\begin{array}{l}\% \text { of total } \\
\text { collection }\end{array}$} & \multirow{2}{*}{$\begin{array}{l}\text { Liter diesel fuel for curbside } \\
\text { collection }\end{array}$} & \multicolumn{2}{|c|}{ Liter diesel fuel for transport to MRF } \\
\hline & & & Truck type & Truck type \\
\hline PET & & $\begin{array}{l}\text { Volume-based } \\
\text { (50\% comp.) }\end{array}$ & $\begin{array}{l}\text { Medium-size truck } \\
\left(16 \mathrm{~m}^{3}\right)\end{array}$ & $\begin{array}{c}\text { Large-size } \\
\text { truck } \\
\left(48 \mathrm{~m}^{3}\right)\end{array}$ \\
\hline Curbside collection & 52 & 28 & & \\
\hline MSW sites and junk yards & 48 & & 6.4 & 2.28 \\
\hline \multicolumn{5}{|l|}{ HDPE } \\
\hline Curbside collection & 63 & 28 & & \\
\hline MSW sites and junk yards & 37 & & 6.4 & 2.28 \\
\hline $\begin{array}{l}\text { Weighted average fuel use for PET } \\
\text { collection }\end{array}$ & & 15.5 & & 2.49 \\
\hline $\begin{array}{l}\text { Weighted average fuel use for HDPE } \\
\text { collection }\end{array}$ & & 17.64 & & 1.85 \\
\hline
\end{tabular}

TABLE 5: Energy requirement for 1 ton of the postconsumer material at the material recovery facility (MRF).

\begin{tabular}{lc}
\hline Incoming material transportation & Energy (Btu) \\
\hline Large truck & 84,000 \\
Single unit truck & 230,000 \\
Total transportation & 22,000 \\
\hline Process energy & \\
Electricity (grid) & 30,000 \\
Diesel & 26,000 \\
Total process & 308,000 \\
\hline
\end{tabular}

TABLE 6: Data for the processing of 1 ton of the postconsumer recycled PET flake.

\begin{tabular}{lc}
\hline Raw materials & \\
Sorted postconsumer PET & $1250 \mathrm{~kg}$ \\
$100 \%$ sodium hydroxide & $24.5 \mathrm{~kg}$ \\
Defoamer & $0.79 \mathrm{~kg}$ \\
Wetting agent & $2.46 \mathrm{~kg}$ \\
Surfactant & $0.98 \mathrm{~kg}$ \\
\hline Energy usage $(\mathrm{kWh})$ & Total energy (Btu) \\
Process energy & $1,467,160$ \\
$\quad$ Electricity & 1200 \\
$\quad$ Propane & $1,468,360$ \\
Total process & 316,000 \\
Incoming transportation energy & $430 \mathrm{kWh}$ \\
$\quad$ Water consumption & $200 \mathrm{liters}$ \\
Environmental emissions & \\
Atmospheric emissions & 0.0424 liters \\
Particulates (PM & \\
Particulates $\left(\mathrm{PM}_{2.5}\right)$ & $0.037 \mathrm{~kg}$ \\
Solid wastes to landfill & $220 \mathrm{~kg}$ \\
\hline Waterborne emissions & \\
BOD & $7.36 \mathrm{~kg}$ \\
COD & $21.4 \mathrm{~kg}$ \\
Suspended solids & $3.01 \mathrm{~kg}$ \\
\hline
\end{tabular}

"system expansion" approaches are used for LCA. The results are presented by the three life-cycle stages: (1) recovery, (2) sorting and separation, and (3) reclaimer operations. Each set of tables and figures shows results for both recycling allocation methods (cut-off and system expansion). The two allocating methods are volume-based.
TABLE 7: Data for the processing of 1 ton of the postconsumer recycled HDPE pellet.

\begin{tabular}{lcc}
\hline Raw materials & & \\
Sorted postconsumer HDPE & $1098 \mathrm{~kg}$ & \\
100\% sodium hydroxide & $0.32 \mathrm{~kg}$ & \\
Defoamer & $1.57 \mathrm{~kg}$ & \\
Wetting agent & $0.59 \mathrm{~kg}$ & \\
Surfactant & $0.81 \mathrm{~kg}$ & \\
Alkaline cleaner & $0.058 \mathrm{~kg}$ & \\
\hline Energy usage & \multicolumn{3}{c}{ Total energy (Btu) } \\
Process energy & & $1,535,000$ \\
$\quad$ Electricity & $450 \mathrm{kWh}$ & 7634 \\
$\quad$ Diesel & $0.176 \mathrm{liters}$ & 8470 \\
$\quad$ Propane & 0.304 liters & $1,551,104$ \\
$\quad$ Total process & & 331,000 \\
Incoming transportation energy & & \\
Water consumption & $240 \mathrm{liters}$ & \\
Environmental emissions & & \\
Atmospheric emissions & & \\
Particulates (PM & & \\
Particulates (PM & & \\
Solid wastes to landfill & $0.05 \mathrm{~kg}$ & \\
Waterborne emissions & $0.032 \mathrm{~kg}$ & \\
\hline Water emission & $140 \mathrm{~kg}$ & \\
BOD & $0.6 \mathrm{~kg}$ & \\
COD & & \\
Suspended solids & $0.62 \mathrm{~kg}$ & \\
Dissolved solids & $0.0031 \mathrm{~kg}$ & \\
\hline
\end{tabular}

The emission results from material production, fuel production, and combustion are considered in this study. Various sources are used to obtain emission quantities based upon the best available data. The atmospheric emissions that typically contribute the majority of the total greenhouse gas impacts to product systems are fossil fuel-derived carbon dioxide, methane, and nitrous oxide. Greenhouse gas impacts are reported as carbon dioxide equivalents $\left(\mathrm{CO}_{2}\right.$ eq.).

Table 8 lists the results of the production of virgin resin to compare the "cut-off" and "system expansion" recycling results. The virgin resin data for PET and HDPE are obtained from several sources, as shown in Table 8. Energy requirements for recycled resin production are shown for PET in Table 9 and for HDPE in Table 10. Energy results for PET are shown by the life-cycle stage in Figure 2(a) and by the 
TABLe 8: Virgin resin data for PET and HDPE production [37].

\begin{tabular}{lccc}
\hline Material & Energy demand $(\mathrm{MJ} / \mathrm{kg})$ & Greenhouse gas emissions $\left(\mathrm{kg} \mathrm{CO} \mathrm{CO}_{2}\right.$ eq. per ton) & Solid waste recycled (kg per ton of resin) \\
\hline PET & 71.2 & 2,746 & 142 \\
HDPE & 79.67 & 1,822 & 74.6 \\
\hline
\end{tabular}

TABle 9: Energy and water use for recycled PET resin (MBtu of energy and liter of water per ton of resin).

\begin{tabular}{|c|c|c|c|c|c|c|}
\hline & Process & Transport & EMR & Total & Total \% & Water use [37] \\
\hline \multicolumn{7}{|c|}{ PET: cut-off, volume-based collection (50\% compaction) } \\
\hline Collection (50\% compaction) & 0.053 & 1.51 & 0 & 1.563 & 14 & 0 \\
\hline Sorting/separation & 0.22 & 0.08 & 0 & 0.3 & 2.7 & 0 \\
\hline Reclaimer processing to flake & 8.3 & 0.92 & 0 & 9.22 & 83 & 405 \\
\hline Total for PET flake & 8.573 & 2.51 & 0 & 11.083 & & 405 \\
\hline Percent by category & 77 & 23 & 0 & 0 & & \\
\hline Conversion of flake to pellet & 4.87 & 0 & & 4.871 & & 0 \\
\hline Total for PET pellet & 13.44 & 2.5 & & 15.94 & & 405 \\
\hline Percent by category & 84.3 & 15.7 & & 100 & & \\
\hline \multicolumn{7}{|c|}{ PET: system expansion, volume-based collection (50\% compaction) } \\
\hline Allocated virgin resin production & 15.7 & 0.8 & 17.3 & 33.8 & 86.58 & 0 \\
\hline Collection (50\% compaction) & 0.028 & 0.78 & 0 & 0.808 & 2.07 & 0 \\
\hline Sorting/separation & 0.12 & 0.45 & 0 & 0.57 & 9.89 & 0 \\
\hline Reclaimer processing to pellet & 3.4 & 0.46 & 0 & 3.86 & 9.89 & 189 \\
\hline Total for PET flake & 19.248 & 2.49 & 17.3 & 39.038 & & 189 \\
\hline Percent by category & 49 & 6 & 44 & & & \\
\hline Conversion of flake to pellet & 2.39 & 0 & 0 & 2.39 & & 0 \\
\hline Total for PET pellet & 21.638 & 2.49 & 17.3 & 41.428 & & 189 \\
\hline Percent by category & 52.23 & 6.01 & 42 & 52.23 & & \\
\hline
\end{tabular}

TABLE 10: Energy and water use for recycled HDPE resin (MBtu of energy and liter of water per ton of resin).

\begin{tabular}{|c|c|c|c|c|c|c|}
\hline & Process & Transport & EMR & Total & Total \% & Water use [37] \\
\hline \multicolumn{7}{|c|}{ HDPE: cut-off, volume-based collection (50\% compaction) } \\
\hline Collection (50\% compaction) & 0.013653 & 1.69 & 0 & 1.563 & 18.9 & 0 \\
\hline Sorting/separation & 0.31 & 0.119 & 0 & 0.429 & 5.2 & 0 \\
\hline Reclaimer processing to pellet & 5.4 & 0.87 & 0 & 6.27 & 75.9 & 426 \\
\hline Total for HDPE pellet & 5.72 & 2.68 & 0 & 8.262 & & 426 \\
\hline Percent by category & 69.2 & 32.2 & 0 & 0 & & \\
\hline \multicolumn{7}{|c|}{ HDPE: system expansion, volume-based collection (50\% compaction) } \\
\hline Allocated virgin resin production & 13.58 & 0.55 & 24.8 & 38.93 & 89.91 & 0 \\
\hline Collection ( $50 \%$ compaction) & 0.007 & 0.92 & 0 & 0.927 & 2.14 & 0 \\
\hline Sorting/separation & 0.167 & 0.056 & 0 & 0.223 & 0.52 & 0 \\
\hline Reclaimer processing to pellet & 2.7 & 0.52 & 0 & 3.22 & 7.44 & 216 \\
\hline Total for HDPE pellet & 16.454 & 2.046 & 24.8 & 43.3 & & 216 \\
\hline Percent by category & 38.00 & 4.73 & 57.27 & 0 & & \\
\hline
\end{tabular}

energy category in Figure 2(b), while HDPE energy results are shown in Figures 3(a) and 3(b).

Table 9 and Figure 2 show the LCA results for 1 ton of recycled PET based on the "cut-off" and "system expansion" approaches. Recycled PET flakes offer around $85 \%$ of fuel energy savings compared to the virgin PET based on the "cutoff" approach. Note that, due to the "cut-off" approach, the energy of material resource (EMR, which is the energy content of the fuel material input as raw materials or feedstocks) of the recycled PET flakes is set to zero, whereas for virgin PET flakes, the EMR accounts for about $44 \%$ of its total nonrenewable energy. The energy saving based on "system expansion" is about 50\%. As shown in Figure 4, mechanically recycled PET flakes offer significant greenhouse gas effective savings compared to virgin PET flakes. It has been estimated that PET flake recycling gives a net benefit in greenhouse gas emissions of 1.8 ton of $\mathrm{CO}_{2}$ equivalent per ton of the recycled PET flake. The greenhouse gas of the recycled PET flake is $72 \%$ (mechanical recycling) lower than that of the virgin PET flake. Moreover, Figure 5 shows that greenhouse gas emission of the recycled HDPE pellet is $59 \%$ lower than that of the virgin HDPE pellet.

Solid wastes for recycled resin production are shown for PET in Table 11 and for HDPE in Table 12. The solid waste shown in Figures 6 and 7 shows that the solid wastes disposed from recycled resin sorting and processing steps are much higher than process solid wastes from virgin resin production for both FET and HDPE. The process wastes shown for recycled resin production are largely contaminants that were co-collected with the recovered plastics and were separated from the recovered materials during sorting and separation processes. 


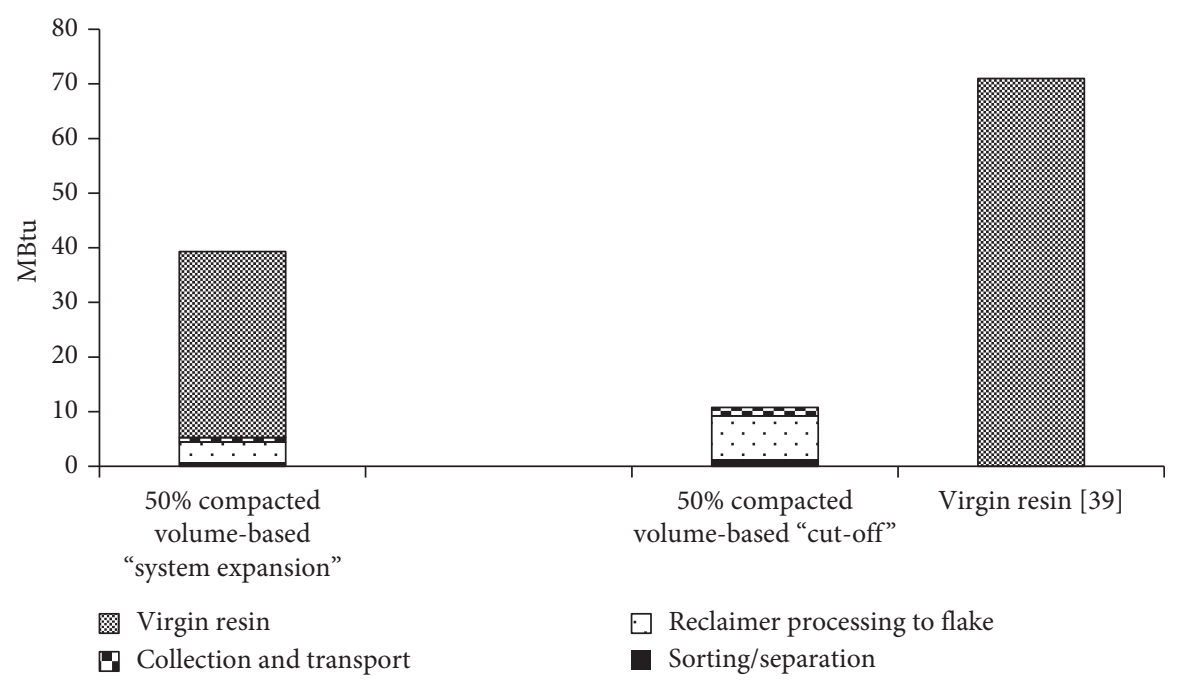

(a)

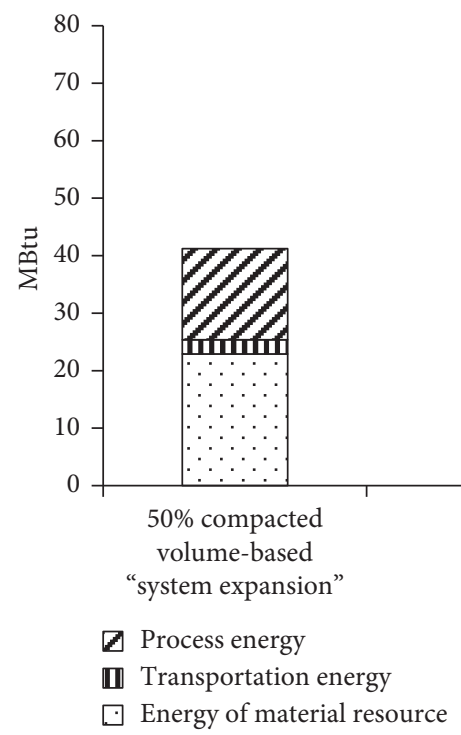

(b)

FIGURE 2: Energy results for production of the recycled PETresin flake (million Btu per ton of resin) by the (a) life cycle stage and (b) energy category.

\section{Discussion}

In this study, two methods were applied to assess the environmental impacts of recycling postconsumer PET and HDPE. The two methods take different perspectives. The "cut-off" approach follows the natural business-to-business boundary and is the most commonly used LCA method for recycled products. It is easy to apply, and no data are required from outside of the investigated product system. The disadvantage is that the method oversimplifies the environmental impact of the "cradle" and the "grave" stages.

The second approach "system expansion" takes the real "cradle" and "grave" and merges two life cycles into one product system with and without recycling. The most important advantage of this method is that it avoids allocation. This method applies life-cycle thinking to the whole system. It is our preferred method for open-loop recycling. The disadvantage of this method is that it is not easy to apply; it results in large systems, and the data requirements from extended product systems can be demanding.

The choice of using LCA results based on the "system expansion" or "cut-off" approach depends on policy-makers. Mainly, there are two perspectives for using LCA results: the manufacturer's point of view and a life-cycle-thinking perspective. The "cut-off" approach fits well to the business because manufacturers concern about reducing the impact of the production process and the suppliers. On the contrary, if the target is to improve material utilization efficiency by avoiding further resource extraction and waste management, the life-cycle-thinking perspective should be used. The overall impact can only be assessed when the entire system and the effect of the system are considered. This can be achieved when using the LCA result based on the "system expansion" approach. The "system expansion" method 


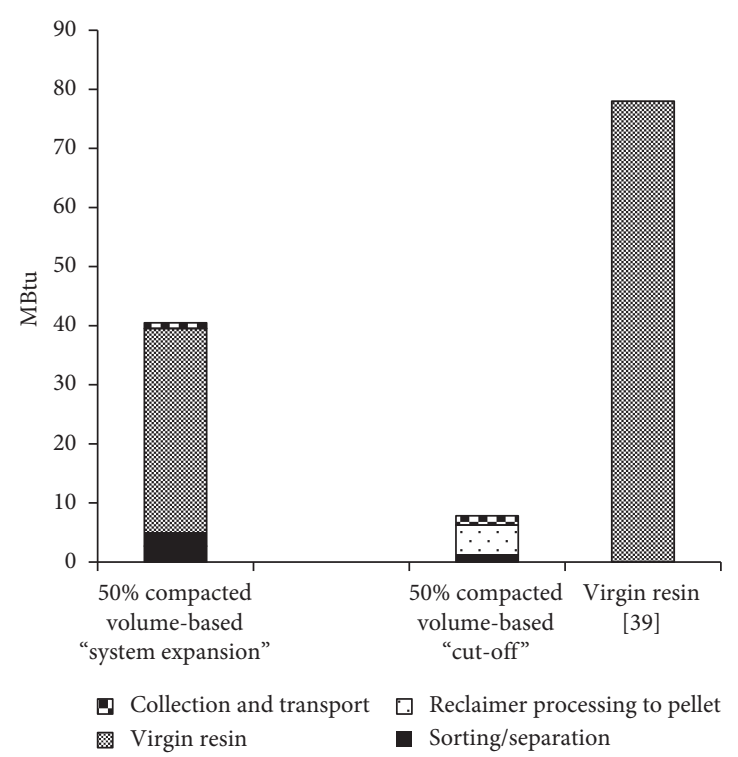

(a)

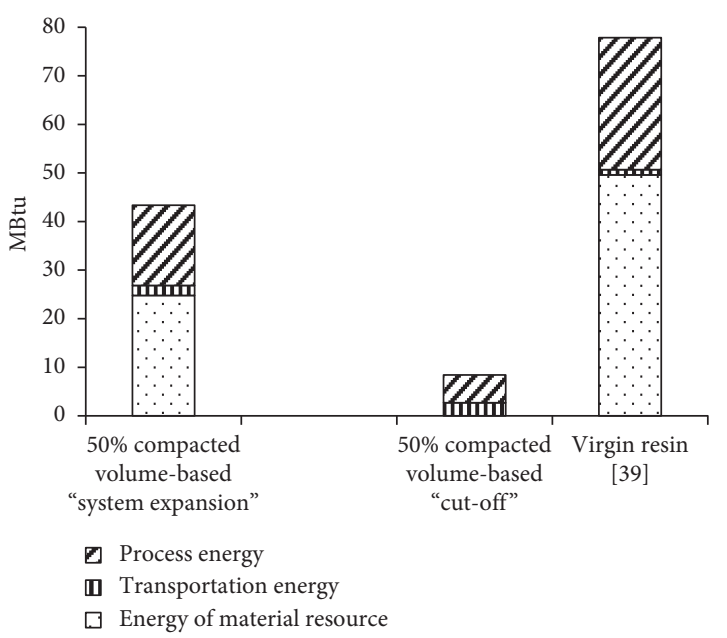

(b)

FIGURE 3: Energy results for production of the recycled HDPE resin pellet (million Btu per ton of resin) by the (a) life cycle stage and (b) energy category.

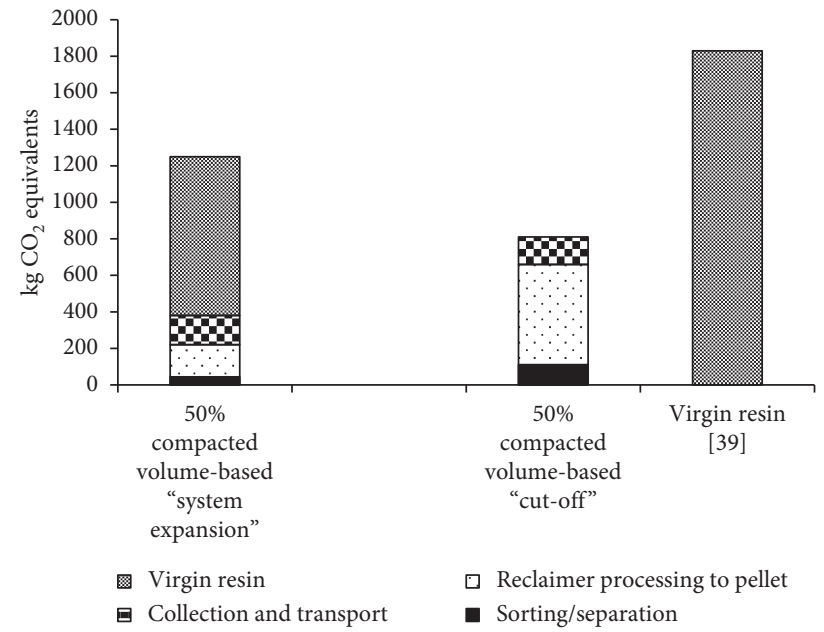

(a)

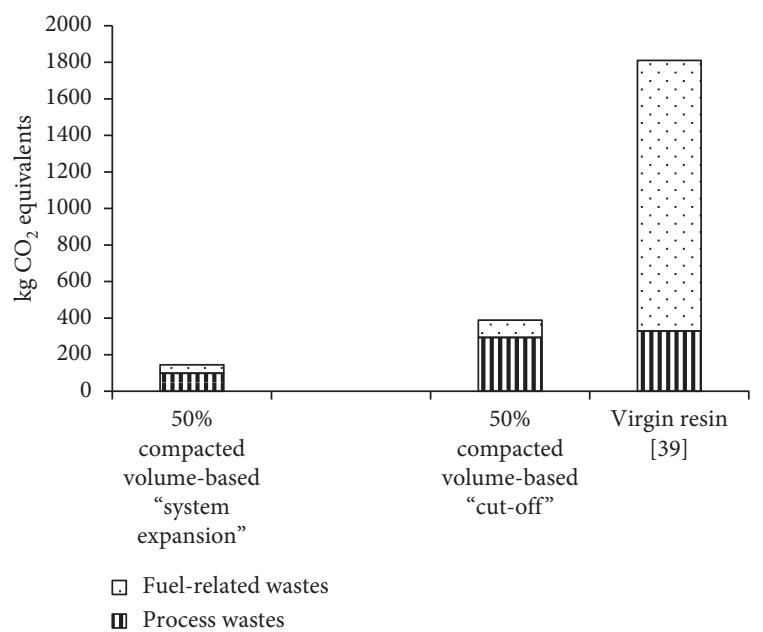

(b)

FIGURE 4: Greenhouse gas results for production of the recycled PET resin flake ( $\mathrm{kg} \mathrm{CO}_{2}$ equivalents per ton of resin) by the (a) life cycle stage and (b) emission category.

reflects the overall efficiency of material utilization without distinguishing different sectors. In other words, individual sectors should apply the "cut-off" approach in order to make proper policies and decisions.

In the "cut-off" method, all virgin material production burdens are assigned to the first use of the material, and the burdens assigned to the recycled resin system begin with recovery of the postconsumer material. All of the burdens for material recovery, transport, separation and sorting, and reprocessing are assigned to the recycled material.

In the "system expansion" allocation method, the burdens for virgin material production, recovery and recycling, and ultimate disposal of the recycled material are merged into the sequential useful lives of the material. This analysis does not define the application in which the recycled resin will be used, and no projections are made about future recovery and recycling of the material.

The results shown in the previous section are fully "rolled-up" data sets. In other words, the burdens for all the processes required to produce recycled resin are included. Fully "rolled-up" data sets include the direct burdens (collecting, transporting, sorting, and reprocessing the material), the upstream burdens for the production and combustion of all fuels used in these processes, and the 


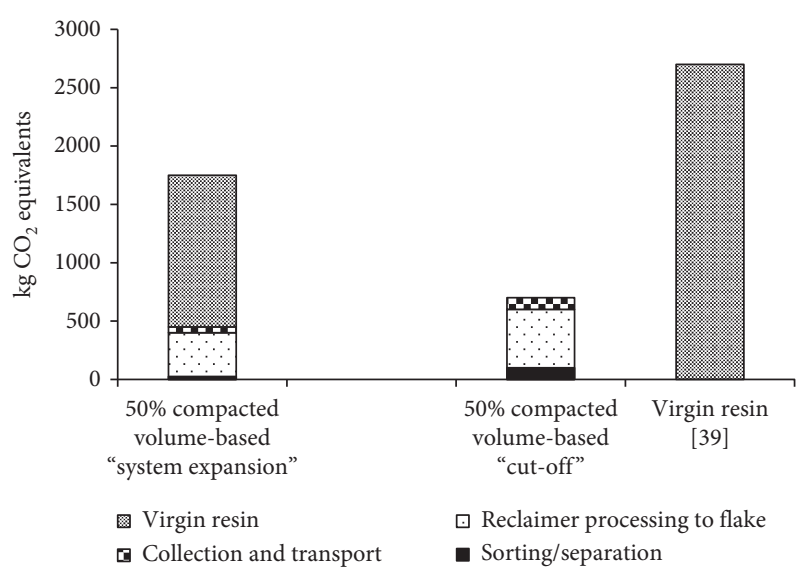

(a)

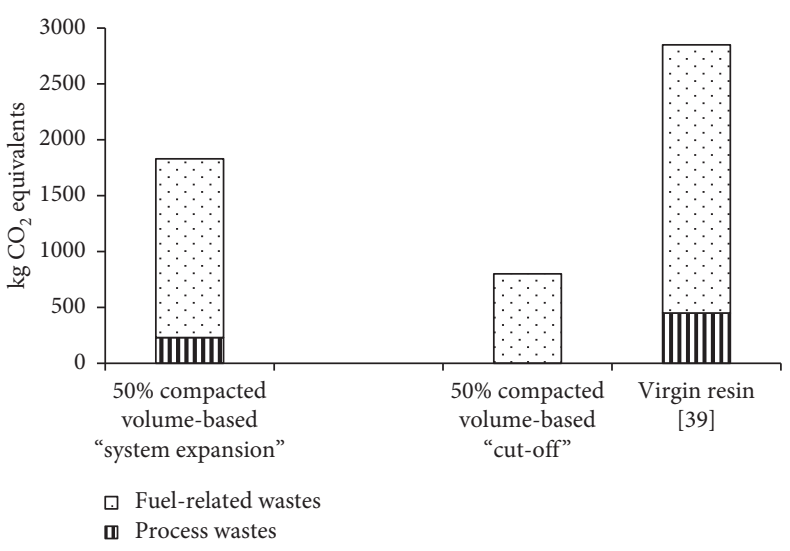

(b)

FIGURE 5: Greenhouse gas results for production of the recycled HDPE resin pellet ( $\mathrm{kg} \mathrm{CO}_{2}$ equivalents per ton of resin) by the (a) life cycle stage and (b) emission category.

TABLE 11: Solid waste for recycled PET resin ( $\mathrm{kg}$ of waste per ton of resin).

\begin{tabular}{|c|c|c|c|c|c|c|}
\hline & \multicolumn{6}{|c|}{ Process solid wastes } \\
\hline & Landfill & Incineration & $\begin{array}{l}\text { Waste-to- } \\
\text { energy }\end{array}$ & $\begin{array}{l}\text { Fuel-related solid } \\
\text { wastes }\end{array}$ & Total & Total \% \\
\hline \multicolumn{7}{|c|}{ PET: cut-off, volume-based collection (50\% compaction) } \\
\hline Collection ( $50 \%$ compaction) & 0 & 0 & 0 & 2.23 & 2.2 & 0.6 \\
\hline Sorting/separation & 73 & 0 & 0 & 1.26 & 74.3 & 21.5 \\
\hline Reclaimer processing to flake & 221 & 0 & 0 & 47.5 & 268.5 & 77.8 \\
\hline Total for PET flake & 294 & 0 & 0 & 50.99 & 345.0 & \\
\hline Percent by category & 77 & 0 & 0 & 0 & & \\
\hline Conversion of flake to pellet & 0 & 0 & 0 & 44 & & \\
\hline Total for PET pellet & 294 & 0 & 0 & 94.99 & 389.0 & \\
\hline Percent by category & 75.70 & 0.00 & 0 & 24 & & \\
\hline \multicolumn{7}{|c|}{$\begin{array}{l}\text { PET: system expansion, volume-based collection ( } 50 \% \\
\text { compaction) }\end{array}$} \\
\hline Allocated virgin resin production & 16.6 & 1.01 & 0 & 54 & 71.6 & 29.1 \\
\hline Collection (50\% compaction) & 0 & 0 & 0 & 1.13 & 1.13 & 0.5 \\
\hline Sorting/separation & 37 & 0 & 0 & 0.64 & 37.6 & 15.3 \\
\hline Reclaimer processing to pellet & 112 & 0 & 0 & 24.1 & 136.1 & 55.2 \\
\hline Total for PET flake & 165.6 & 1.01 & 0 & 79.87 & 246.5 & \\
\hline Percent by category & 67.2 & 0.4 & 0 & 32.4 & & \\
\hline Conversion of flake to pellet & 0 & 0 & 0 & 22 & 22 & \\
\hline Total for PET pellet & 165.6 & 1.01 & 0 & 101.87 & 268.5 & \\
\hline Percent by category & 61.7 & 0.4 & 0.0 & 37.9 & & \\
\hline
\end{tabular}

TABLE 12: Solid waste for recycled HDPE resin (kg of waste per ton of resin).

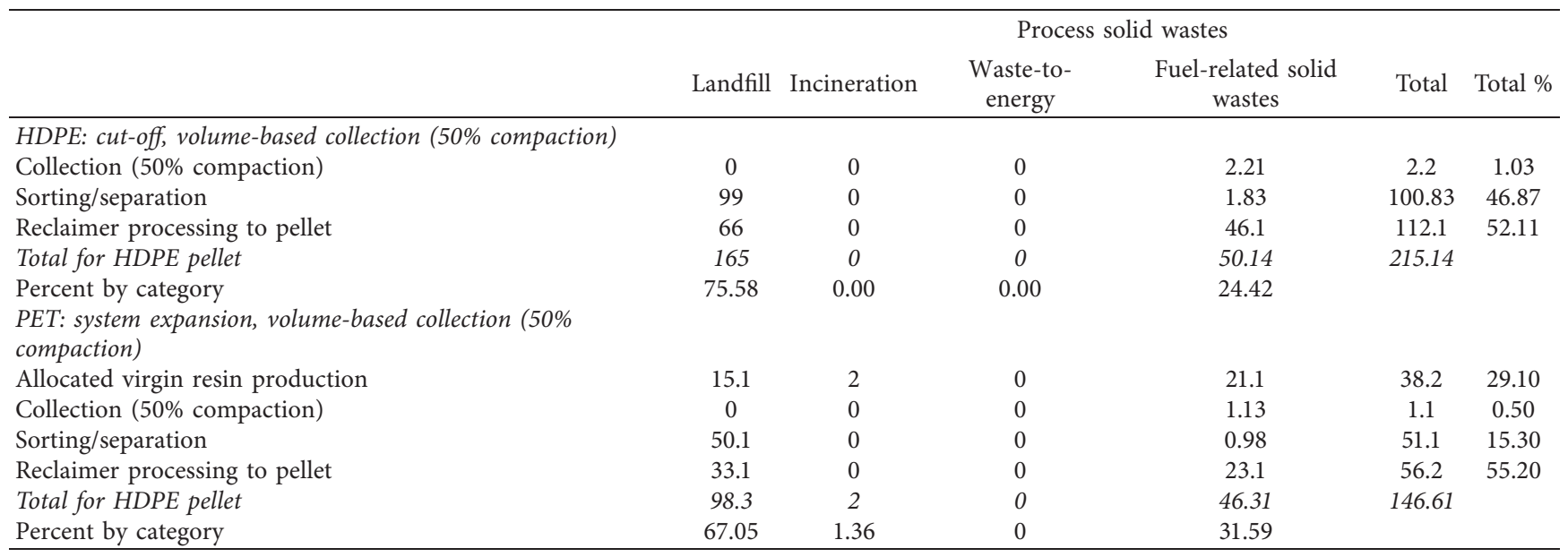




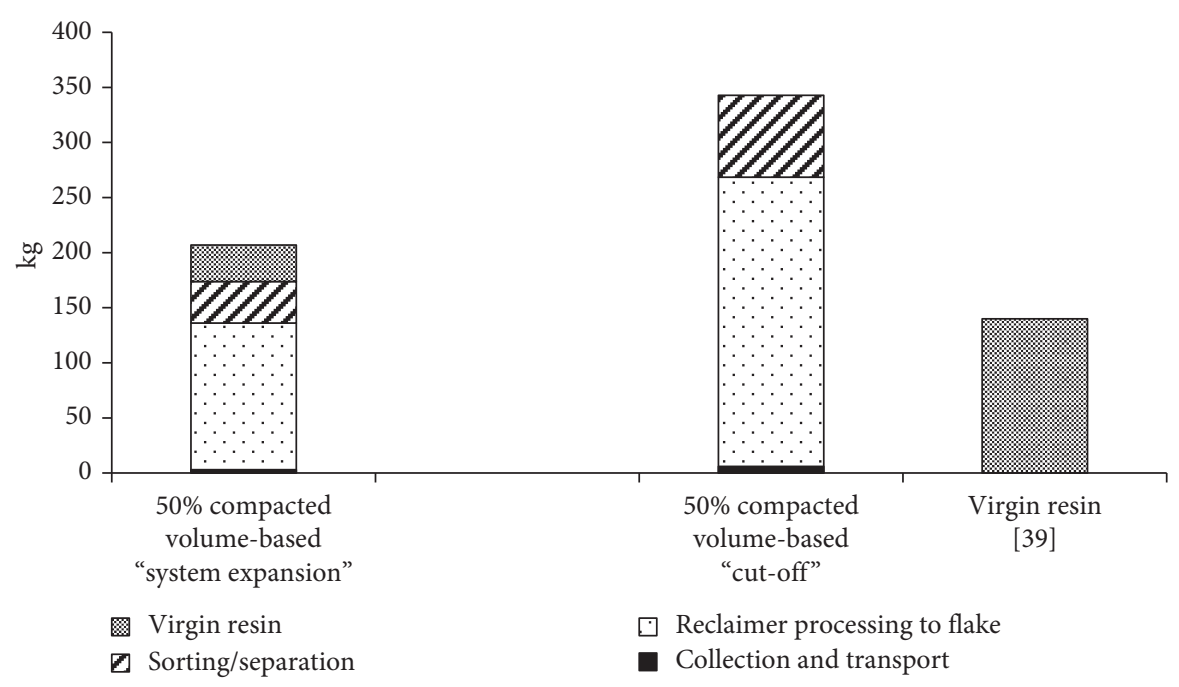

(a)

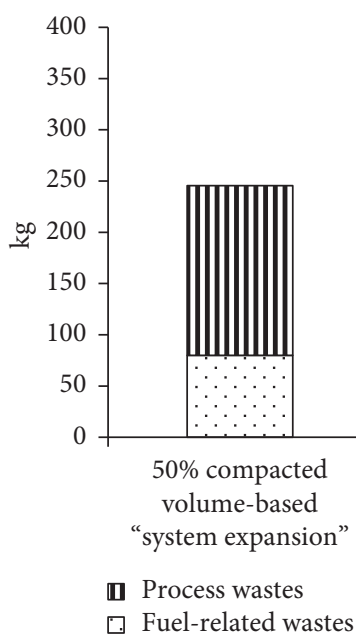

(b)

FIGURE 6: Solid waste results for production of the recycled PET resin flake (kg per ton of resin) by the (a) life cycle stage and (b) solid waste category.

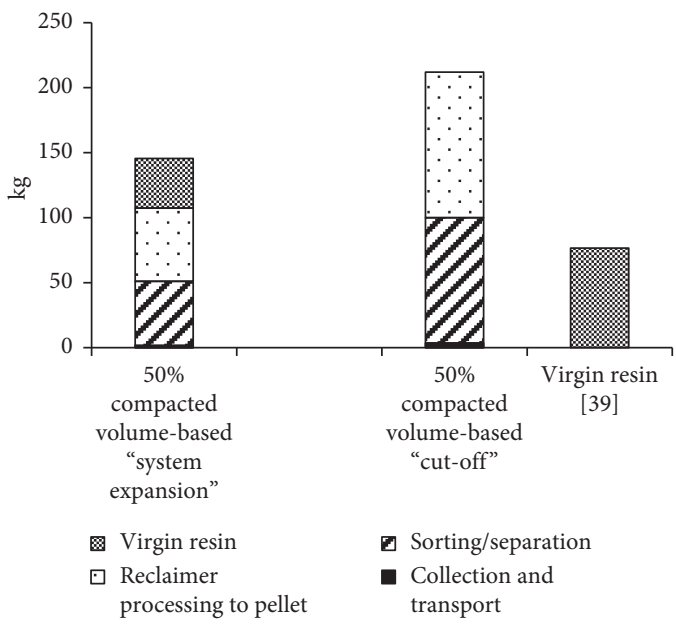

(a)

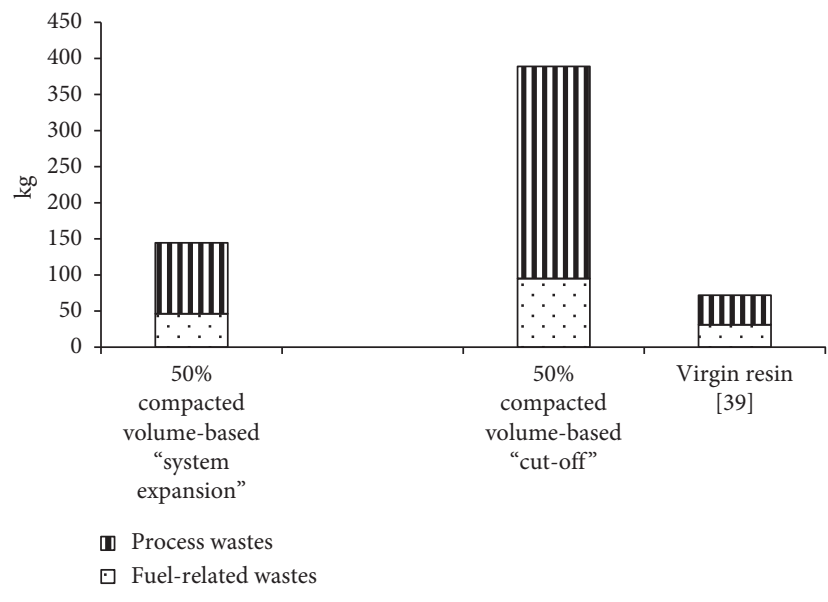

(b)

FIGURE 7: Solid waste results for production of the recycled HDPE resin pellet (kg per ton of resin) by the (a) life cycle stage and (b) solid waste category. 
production of all materials used in these processes. Using fully "rolled-up" data sets allows for a combination of all the related data into a single data set. On the contrary, the total end results cannot be adjusted to reflect any subsequent changes in any individual contributing data sets.

Three energy categories are used and presented in the previous section, namely, (a) process energy, (b) transportation energy, and (c) energy of material resource. Process energy is the energy used to extract and process raw materials and to operate equipment used in the recycling processes. Transportation energy is the energy for the production and consumption of fuels used to collect the postconsumer material and transport the material to the MRF or reclaimer. The energy of material resource (EMR) is assigned to fuel resources such as crude oil and natural gas used as material feedstocks to produce virgin HDPE and PET resin.

4.1. Discussion of Energy Results Based on “Cut-Off” Approach. The total energy requirement for the recycled PET flake is $16 \%$ of virgin PET resin energy based on the cut-off recycling method. Moreover, the recycled HDPE pellets require 11\% as much energy as the virgin HDPE resin. Recycled PET offers $45-85 \%$ of NREU savings compared to the virgin resin. Note that, due to the cut-off approach, the embedded energy (calorific value) of the recycled PET is set to zero, whereas for virgin PET resin, the embedded enegy accounts for about $40 \%$ of its total NREU. Using the cut-off method, no energy of material resource is assigned to the recycled material, and the largest share of the energy requirements for recycled resin production is for reclaimer operations (see Figures 2(a) and 3(a)).

\subsection{Discussion of Energy Results Based on "System Expansion"} Approach. In the system expansion allocation method, the burdens for virgin material production, recovery and recycling, and ultimate disposal of the recycled material are shared among all the sequential useful lives of the material. For the purpose of presenting cradle-to-gate "system expansion" results for recycled resin, this analysis uses an assumption of two useful lives of the material (resin is used in a virgin product and then in a recycled product and then disposed), so the burdens for virgin material production, postconsumer recovery, and reprocessing are divided between the virgin and recycled uses of the material. Based on the system expansion recycling allocation method, the total energy requirement for the recycled PET flake is $60 \%$ of virgin resin energy. Moreover, LCA results show that recycled HDPE pellets require $57 \%$ as much energy as virgin pellets based on the "system expansion" method.

The rolled-up "system expansion" results shown in the previous section represent one scenario for the recycled resin that is based on two useful lives of the resin material (i.e., once in a virgin product and once in a recycled product and then disposed). The amount of postconsumer resin shown as an input to reprocessing in Tables 6 and 7 is assigned half of its virgin resin production loads (the other half is allocated to the first use of the material in a virgin product). If the recycled resin is being used in a plastic product that is recovered and recycled at the end of its life, the total useful number of lives of the material would be three (virgin product, first recycled product, and second recycled product and then disposed), and one-third of the virgin resin production burdens would be allocated to each useful life of the resin.

4.3. Water Usage. Results for quantitates of water used for recycled resin production are shown in Table 9 for PET and in Table 10 for HDPE. It is worth mentioning that water use for virgin resin production processes was not included. Moreover, it was assumed that there is no water use for material sorting and separation operations, although in some cases flotation separation was used. The results for water use are only for postconsumer plastic processing (washing operations only).

4.4. Solid Waste. Solid wastes for recycled resin production are shown in Tables 11 and 12 and Figures 6 and 7. Process wastes listed are wastes resulted from (a) process steps used to extract raw materials and processing them into usable products and (b) recycling processes: collecting, sorting, separating, and processing post-consumer material. Fuelrelated wastes are the wastes resulting from the production and consumption of fuels used for process or transportation energy. This includes wastes associated with the combustion of fuels used for operations at the MRF, PRF, or reclaimer facility, as well as wastes associated with the fuel used to collect the postconsumer material and transport it to MRFs, PRFs, and reclaimers. No postconsumer wastes are included.

As mentioned previously, the solid waste for recycling resin is much higher than process solid wastes from virgin resin production. The reason behind this is the large amount of co-collected materials with the recovered plastic. The majority of this waste is not caused by recycling processes. The majority of the solid waste disposed from the sorting and processing operations is the material that would have been disposed as waste regardless of whether postconsumer plastic recycling takes place or not. Moreover, MRFs and reclaimers practically recover all the usable incoming materials including materials other than the desired resin. It is worth mentioning that if the co-collected wastes are excluded, the solid wastes for recycled resin production are lower than the solid wastes for virgin resin production. More specifically, without sorting and reclaimer process wastes, the results presented in Table 11 show that solid waste plastic is only $35 \%$ of the virgin PET resin based on the "cut-off" recycling method and 56\% of the virgin PET resin based on the "system expansion" method. Moreover, excluding sorting and reclaimer process wastes, the results presented in Table 11 show that solid waste plastic is only $35 \%$ of the virgin PET resin based on the "cut-off" recycling method and $66 \%$ of the virgin PET resin based on the "system expansion" recycling method. As for HDPE, excluding sorting and reclaimer process wastes, the results presented in Table 12 show that solid waste plastic is only $65 \%$ of the virgin HDPE resin 
TABLE 13: Comparison of PET flake and HDPE pellet production with other studies.

\begin{tabular}{|c|c|c|c|c|}
\hline \multicolumn{5}{|l|}{ Output: 1 ton of the recycled PET flake } \\
\hline & Present study & Arena et al. [11] & Shen et al. [17] & Detzel et al. [38] \\
\hline Nonrenewable energy (GJ/ton flake) & 11.3 & 7.97 & 13 & NA \\
\hline (kg $\mathrm{CO}_{2}$ eq./ton flake) & 660 & 635 & $310-720$ & NA \\
\hline Yield of PET flakes (or material efficiency, wt.\%) & 80 & 76 & 75 & 80 \\
\hline \multicolumn{5}{|l|}{ Output: 1 ton of the recycled HDPE pellet } \\
\hline & Present study & & Kreiger et al. [39] & \\
\hline Energy demand $(\mathrm{MJ} / \mathrm{kg})$ & 8.65 & & 8.74 & \\
\hline (kg $\mathrm{CO}_{2}$ eq./ton HDPE) & 630 & & 520 & \\
\hline
\end{tabular}

based on the "cut-off" method and $60 \%$ of the virgin HDPE resin based on the "system expansion" recycling method.

4.5. Greenhouse Gas (GHG) Emissions. The emissions reported in this analysis include those associated with the production of materials and production and combustion of fuels. Atmospheric emissions include emissions from both processes and emissions associated with the combustion of fuels. Process emissions include emissions associated with collecting, transporting, sorting, and reprocessing the material during its life cycle, while fuel-related emissions are those associated with the combustion of fuels used for process energy and transportation energy.

Total emissions for the "cut-off" approach include the emissions for collection and transport, sorting and separation, and reprocessing. Total emissions for the "system expansion" method include half of the emissions for virgin resin production and half of the emissions for collection and transport, sorting and separation, and reprocessing.

The LCA results show that the majority of the GHG emissions are fuel-related. No process GHG emissions were reported for the collection, sorting and separation, and reclaimer processes; the only GHG emissions from these operations are associated with fuel use. There are process GHG emissions for the production of virgin resin, so the "system expansion" recycled resin results include a share of these process emissions. Regardless of the recycling methodology used, the recycled resin systems show lower GHG emissions than virgin resin production. More specifically, the results presented in Figures 7(a) and 7(b) show that the total $\mathrm{CO}_{2}$ eq. emission for recycled HDPE resin production is $36 \%$ and $68 \%$ of the virgin HDPE resin based on "cut-off" and "system expansion" methods, respectively. On the contrary, the results presented in Figures 5(a) and 5(b) show that the total $\mathrm{CO}_{2}$ eq. emission for recycled PET resin production is $30 \%$ and $67 \%$ of the virgin PET resin based on "cut-off" and "system expansion" methods, respectively. Furthermore, the largest share of the greenhouse gas (GHG) emissions for recycled resin production is due to reclaimer operations.

4.6. Comparison with Other Studies. Most PET recycling studies focused on waste management rather than the production of recycled products. As mentioned previously, a few studies reported inventory data of PET flake production $[11,17,38]$. The comparison of flake production shows that the inventory data and the results reported by this study fit well with those reported by Shen et al. [17], Arena et al. [11], and Detzel et al. [38] (see Table 13).

\section{Conclusions}

In this study, the environmental impacts of recycling PET and HDPE were assessed. The LCA results were compared with the ecoprofile of virgin PET flakes and HDPE pellets. Two methods were applied for this analysis: "system expansion" and "cut-off" methods based on 50\% compacted volume. LCA results show that total energy requirements for the recycled PET flake are $14 \%$ to $17 \%$ of the virgin PET flake based on the "cut-off" recycling method and $57 \%$ of virgin resin based on the "system expansion" method. For HDPE, recycled HDPE pellets require $12 \%$ to $13 \%$ energy of virgin HDPE resin based on the "cut-off" recycling method, while they require $62 \%$ based on the "system expansion" method. Moreover, based on the LCA results, it can be concluded that greenhouse gas emission saving between $25 \%$ and $75 \%$ can be achieved by recycling PET and HDPE. We found that the amount of savings depends on the allocation method and system boundaries. Furthermore, it is clear that the "cut-off" method is a simple straightforward approach, which can be easily applied because it focuses on the recycled product only. It is found that the "cut-off" approach reflects the current environmental policy. The "system expansion" recycling method is not an easy method to apply because it requires detailed data outside of the life cycle of the investigated product. The main difference in the life cycle impacts between resin made of recycled plastics and virgin plastics is due to the result of avoiding the manufacturing of virgin plastics. Based on LCA results, it can be concluded that PET and HDPE recycling offers significant environmental benefits over the single-use virgin materials and can improve ecoefficiency.

\section{Data Availability}

The data used to support the findings of this study are available from the corresponding author upon request.

\section{Conflicts of Interest}

The author declares no conflicts of interest. 


\section{References}

[1] L. Shen and E. Worrell, Chapter 13-Plastic Recycling Handbook of Recycling, 2014.

[2] Plastics -the Facts 2018, An Analysis of European Plastics Production, Demand and Waste data, Plastics Europe, Brussels, Belgium, 2018.

[3] S. Perdon, "Sustainable development in practice: case studies for engineers and scientists," in Introduction to Sustainable Development (Chapter 1), A. Azapagic, S. Perdon, and R. Clift, Eds., Wiley, Hoboken, NJ, USA, first edition, 2004.

[4] JCR, Plastics Recycling. Final Assessment Report, St. Catherine's College JCR, University of Oxford, Oxford, UK, 2006, http://hadriel.caths.cam.ac.uk/jcr/html/modules.php.

[5] Waste Watch \& Recoup, Waste Watch 2003 Plastics in the UK Economy, Waste Watch \& Recoup, London, UK, 2003.

[6] D. Lazarevic, E. Aoustin, N. Buclet, and N. Brandt, "Plastic waste management in the context of a European recycling society: comparing results and uncertainties in a life cycle perspective," Resources, Conservation and Recycling, vol. 55, no. 2, pp. 246-259, 2010.

[7] P. A. Wäger and R. Hischier, "Life cycle assessment of postconsumer plastics production from waste electrical and electronic equipment (WEEE) treatment residues in a Central European plastics recycling plant," Science of The Total Environment, vol. 529, pp. 158-167, 2015.

[8] P. A. Wäger, R. Hischier, M. Eugster, and M. Eugster, "Environmental impacts of the Swiss collection and recovery systems for waste electrical and electronic equipment (WEEE): a follow-up," Science of The Total Environment, vol. 409, no. 10, pp. 1746-1756, 2011.

[9] M. A. Al-Maadeed, N. K. Madi, R. Kahraman, A. Hodzic, and N. G. Ozerkan, "An overview of solid waste management and plastic recycling in Qatar," Journal of Polymers and the Environment, vol. 20, no. 1, pp. 186-194, 2012.

[10] J. Morris, "Recycling versus incineration: an energy conservation analysis," Journal of Hazardous Materials, vol. 47, no. 1-3, pp. 277-293, 1996.

[11] U. Arena, M. L. Mastellone, and F. Perugini, "Life cycle assessment of a plastic packaging recycling system," The International Journal of Life Cycle Assessment, vol. 8, no. 2, pp. 92-98, 2003.

[12] F. Perugini, M. L. Mastellone, and U. Arena, "A life cycle assessment of mechanical and feedstock recycling options for management of plastic packaging wastes," Environmental Progress, vol. 24, no. 2, pp. 137-154, 2005.

[13] B. Simon, M. Ben Amor, and R. Földényi, "Life cycle impact assessment of beverage packaging systems: focus on the collection of post-consumer bottles," Journal of Cleaner Production, vol. 112, pp. 238-248, 2015.

[14] Department of Environment and Conservation (NSW), Benefits of Recycling, Department of Environment and Conservation (NSW), Parramatta. Australia, 2005.

[15] M. Patel, N. von Thienen, E. Jochem, and E. Worrell, "Recycling of plastics in Germany," Resources, Conservation and Recycling, vol. 29, no. 1-2, pp. 65-90, 2000.

[16] J. Hopewell, R. Dvorak, and E. Kosior, "Plastics recycling: challenges and opportunities," Philosophical Transactions of the Royal Society B: Biological Sciences, vol. 364, no. 1526, pp. 2115-2126, 2009.

[17] L. Shen, E. Worrell, and M. K. Patel, "Open-loop recycling: a LCA case study of PET bottle-to-fibre recycling fibre recycling resources," Resources, Conservation and Recycling, vol. 55, no. 1, pp. 34-52, 2010.
[18] S. Burnley, T. Chilton, and S. Nesaratnam, "A life cycle assessment of the closed-loop recycling and thermal recovery of post-consumer PET," Resources, Conservation and Recycling, vol. 54, no. 12, pp. 1241-1249, 2010.

[19] S. Rajendran, L. Scelsi, A. Hodzic, C. Soutis, and M. A. AlMaadeed, "Environmental impact assessment of composites containing recycled plastics," Resources, Conservation and Recycling, vol. 60, pp. 131-139, 2012.

[20] European Environment Agency, The European Environment State and Outlook, European Environment Agency, Copenhagen, Denmark, 2005.

[21] E. Ram'irez-Vargas and Z. Sandoval-Arellano, "Compatibility of HDPE/post-consumer HDPE blends using compatibilizing agents," Journal of Applied Polymer Science, vol. 100, pp. 3696-3706, 2006.

[22] A. K. Jassim, "Recycling of polyethylene waste to produce plastic cement," Procedia Manufacturing, vol. 8, pp. 635-642, 2017.

[23] R. Pfaendner, "Improving the quality of recycled materials," Kunststoffe International, vol. 105, no. 12, pp. 41-44, 2015.

[24] N. K. Madi, "Thermal and mechanical properties of injection molded recycled high density polyethylene blends with virgin isotactic polypropylene," Materials \& Design, vol. 46, pp. 435-441, 2013.

[25] M. Alzerreca, M. Paris, O. Boyron, D. Orditz, G. Louarn, and O. Correc, "Mechanical properties and molecular structures of virgin and recycled HDPE polymers used in gravity sewer systems," Polymer Testing, vol. 46, pp. 1-8, 2015.

[26] P. Oblak, J. Gonzalez-Gutierrez, B. Zupančič, A. Aulova, and I. Emri, "Processability and mechanical properties of extensively recycled high density polyethylene," Polymer Degradation and Stability, vol. 114, pp. 133-145, 2015.

[27] K. A. Elamri, O. Harzallah, and A. Lallam, "Characterization of recycled/virgin PET polymers and their composites," American Journal of Nano Research and Application, vol. 3, no. 4-1, pp. 11-16, 2015.

[28] A. Laurent, I. Bakas, J. Clavreul et al., "Review of LCA studies of solid waste management systems-part I: lessons learned and perspectives," Waste Management, vol. 34, no. 3, pp. 573-588, 2014.

[29] Report, COR-2014-01462-00-02-TCD-TRA (FR) 1/20.

[30] R. B. Clements, Complete Guide to ISO 14000, Prentice Hall Direct, Upper Saddle River, NJ, USA, 1996.

[31] A. Laurent, J. Clavreul, A. Bernstad et al., "Review of LCA studies of solid waste management systems-part II: methodological guidance for a better practice," Waste Management, vol. 34, no. 3, pp. 589-606, 2014.

[32] A. Azapagic and R. Clift, "Allocation of environmental burdens in multiple-function systems," Journal of Cleaner Production, vol. 7, no. 2, pp. 101-119, 1999.

[33] R. Frischknecht, N. Jungbluth, H.-J. Althaus et al., Overview and Methodology. Port No. 1, Swiss Centre for Life Cycle Inventories, Duebendorf, Switzerland, 2007.

[34] R. Frischknecht, "LCI modelling approaches applied on recycling of materials in view of environmental sustainability, risk perception and eco-efficiency," The International Journal of Life Cycle Assessment, vol. 15, no. 7, pp. 666-671, 2010.

[35] University of Birmingham, UK, 2011, http://www.clavertonnergy.com/wordpress/wp-content/uploads/2012/08/the_energy_ and_fuel_data_sheet1.pdf.

[36] EPA 430-R-08-005, Inventory of U.S. Greenhouse Gas Emissions and Sinks: 1990-2006, EPA, Washington, DC, USA, 2008. 
[37] G. Hammond and C. Jones, Inventory of Carbon \& Energy (ICE) Version 1.6a, University of Bath, Bath, UK, 2008.

[38] A. Detzel, J. Giegrich, M. Krüger, S. Möhler, and A. Ostermayer, Life Cycle Assessment of PET-Ems Taking into Account Secondary Products, IFEU GmbH, Heidelberg, Germany, 2004.

[39] M. A. Kreiger, M. L. Mulder, A. G. Glover, and J. M. Pearce, "Life cycle analysis of distributed recycling of post-consumer high density polyethylene for 3-D printing filament," Journal of Cleaner Production, vol. 70, pp. 90-96, 2014. 